[2] Meyer A, Sandler DP, Beane Freeman LE, Hofmann JN, Parks CG. Pesticide Exposure and Risk of Rheumatoid Arthritis among Licensed Male Pesticide Applicators in the Agricultural Health Study. Environ Health Perspect 2017;14;125(7):077010.

Disclosure of Interest: None declared

DOI: 10.1136/annrheumdis-2018-eular.6215

\section{SAT0740-HPR PARITY AND THE RISK OF DEVELOPING RHEUMATOID ARTHRITIS: EVIDENCE FROM THE MALAYSIAN EPIDEMIOLOGICAL INVESTIGATION OF RHEUMATOID ARTHRITIS CASE-CONTROL STUDY}

C.L. Too ${ }^{1,2}$, A.F. Nurul Aain ${ }^{1}$, L.K. Tan ${ }^{3}$, I.S. Lau ${ }^{4}$, M.L. Nor Asiah ${ }^{5}$, S. Salsabil ${ }^{6}$, H. Heselynn ${ }^{7}$, S. Nor Shuhaila ${ }^{7}$, S. Wahinuddin ${ }^{8}$, S.C. Gun ${ }^{9}$, B. Eashwary ${ }^{7}$, M S. Mohd Shahrir ${ }^{10}$, M. Ainon ${ }^{11}$, R. Azmillah ${ }^{4}$, O. Muhaini ${ }^{12}$, B. Camilla ${ }^{13}$, L. Padyukov ${ }^{2}$, L. Alfredsson ${ }^{13}$, L. Klareskog ${ }^{2}$, M.L. Shahnaz ${ }^{14} .{ }^{1}$ Allergy and Immunology Research Center, Institute for Medical Research, Jalan Pahang, Malaysia; ${ }^{2}$ Department of Medicine, Rheumatology Unit, Karolinska Institutet and Karolinska University Hospital, Stockholm, Sweden; ${ }^{3}$ Immunogenetic Unit, Allergy and Immunology Research Center, Institute for Medical Research, Institute for Medical Research, Jalan Pahang; ${ }^{4}$ Department of Medicine, Selayang Hospital, Selangor, ${ }^{5}$ Institute of Public Health; ${ }^{6}$ Allergy and Immunology Research Center, Institute for Medical Research, Kuala Lumpur, ${ }^{7}$ Department of Medicine, Putrajaya Hospital, Wilayah Persekutuan; ${ }^{8}$ Faculty of Medicine, Universiti Kuala Lumpur Royal College of Medicine Perak, Ipoh; ${ }^{9}$ Department of Medicine, Hospital Tunku Ja'afar Seremban, Seremban; ${ }^{10}$ Faculty of Medicine, Universiti Kebangsaan Malaysia Medical Center, Wilayah Persekutuan; ${ }^{11}$ Department of Medicine, Tengku Ampuan Afzan Hospital, Pahang; ${ }^{12}$ Department of Medicine, Hospital Raja Perempuan Bainun, Perak, Malaysia; ${ }^{13}$ Institute of Environmental Medicine, Karolinska Institutet, Stockholm, Sweden; ${ }^{14}$. Level 12th, Block E7, Parcel E, Federal Government Administrative Center, Ministry of Health Malaysia, Kuala Lumpur, Malaysia

Background: Recent evidence from epidemiological studies has suggested that reproductive factors may play an important role for rheumatoid arthritis (RA) development. An inverse association was reported in several studies between parity and risk of RA.

Objectives: We investigated the association between parity and risk of anti-citrullinated peptide antibody (ACPA)-positive RA and ACPA-negative RA in the Malaysian population.

Methods: Data from the Malaysian Epidemiological Investigation of rheumatoid Arthritis (MyEIRA) population-based case control study involving 902 female early RA and 906 age and residential area-matched female controls were analysed. Parity history was assessed through a questionnaire. Parous women were compared with nulliparous women, by calculating odds ratio (OR) with $95 \%$ confidence intervals $(\mathrm{Cl})$.

Results: Our findings demonstrated that parity was significantly associated with decreased risk of developing RA in the Malaysian population (RA versus controls, $82 \%$ vs. $89 \%$, OR $0.58,95 \% \mathrm{Cl} 0.44-0.77, \mathrm{p}<0.001)$. The association between parity and risk of RA was uniformly observed for ACPA-positive RA (OR 0.58, 95\% Cl 0.43-0.80, $\mathrm{p}<0.001$ ) and ACPA-negative RA (OR 0.58, 95\% Cl 0.40$0.84, p<0.01$ ) subsets, respectively. Compared with nulliparous women, the decreased risk was pronounced at the level of three and more live births for both ACPA-positive (OR $0.48,95 \% \mathrm{Cl} 0.34-0.66, \mathrm{p}<0.001$ ) and ACPA-negative RA (OR $0.46,95 \% \mathrm{Cl} 0.31-0.68, \mathrm{p}<0.001$ ) subsets.

Conclusions: Our data demonstrated that parity and level of three and more live births was associated with decreased risk of developing RA in the Malaysian population. The associated decrease risk was observed in both ACPA-positive and ACPA-negative RA subsets.

\section{REFERENCES:}

[1] Orellano C, Saevardottir S, Klareskog L, Karlson EW, Alfredsson L, Bengtsson C. Parity and the risk of developing rheumatoid arthritis: results from the Swedish Epidemiological Investigation of Rheumatoid Arthritis study. Ann Rheum Dis 2014;73:752-755.

[2] Ren L, Guo P, Sun Q, Liu H, Chen Y, Huang Y and Cai X. Number of parity and risk of rheumatoid arthritis in women: A dose-response meta-analysis of observational studies. J. Obstet. Gynaecol. Res 2017;43(9):14281440.

Disclosure of Interest: None declared DOI: 10.1136/annrheumdis-2018-eular.6166

\section{SAT0741-HPR COGNITIVE-BEHAVIOURAL AND SOCIAL FACTORS DO NOT PREDICT RECURRENT SECONDARY HEALTH CARE USE IN PATIENTS WITH FIBROMYALGIA: A LONGITUDINAL STUDY}

J.E. Vriezekolk ${ }^{1}$, V.M. Vervoort ${ }^{1}$, T.C. olde Hartman ${ }^{2}$, T. van Helmond ${ }^{1}$, W.H. van der Laan ${ }^{3}$, R. Geenen ${ }^{4}$, C.H. van den Ende ${ }^{1} .{ }^{1}$ Rheumatology, Sint Maartenskliniek; ${ }^{2}$ Primary and Community Care, Radboud University Nijmegen Medical Centre, Nijmegen; ${ }^{3}$ Rheumatology, Sint Maartenskliniek, Woerden; ${ }^{4}$ Psychology, Utrecht University, Utrecht, Netherlands

Background: Health care use in fibromyalgia (FM) is relatively high. Besides disease-related variables, cognitive-behavioural factors have been concurrently associated with health care use. It is unknown whether cognitive-behavioural and social factors also predict future health care use.

Objectives: To identify cognitive-behavioural and social factors predicting recurrent secondary health care use in FM.

Methods: Data were drawn from a prospective cohort of recently diagnosed patients with fibromyalgia ( $n=199)$, spanning 18 months. Patients were recruited after receiving their diagnosis and protocolled treatment advice by a rheumatologist. Using self-report questionnaires, health care use, cognitive-behavioural (i.e. illness cognitions, pain coping, coping flexibility), social (i.e. invalidation by family, spousal responses to pain and well behaviour), sociodemographic and diseaserelated variables including comorbidities, severity of FM, and depressive and anxiety symptoms were collected. Primary outcome was recurrent secondary health care use at 18 months follow-up defined as the use or non-use for each of the following four categories of secondary health care: consultation with medical specialists, diagnostic procedures, admission to health care institutions, and multimodal treatment program. A patient was considered a recurrent secondary health care user, if secondary health care from at least one of the four categories was used in the past six months. Univariate and multivariate logistic regression models examined whether and which variables were predictors for recurrent secondary health care use. Internal validation was performed to correct for over-fit of the final multivariate model.

Results: Recurrent secondary health care use was lower than initial secondary health care use. Univariate analysis showed that having at least one comorbidity, depressive feelings, severe consequences of fibromyalgia, low personal contro and a high severity of fibromyalgia predicted recurrent secondary health care use. In the multivariate model, having at least one comorbidity was the only remaining predictor for recurrent secondary health care use.

Conclusions: Our results suggest that the existence of comorbidities as communicated by the patient is the strongest warning signal for recurrent secondary health care use in FM. There seems no value in using cognitive-behavioural and social factors for early identification of patients with FM at risk for recurrent secondary health care use.

Disclosure of Interest: None declared

DOI: 10.1136/annrheumdis-2018-eular.2471

\section{SAT0742-HPR EUROPEAN LEAGUE AGAINST RHEUMATISM RECOMMENDATIONS FOR THE ROLE OF THE NURSE (EULAR-RN) IN THE MANAGEMENT OF CHRONIC INFLAMMATORY ARTHRITIS (CIA): RESULTS OF PATIENTS IN NORDIC COUNTRIES}

M.L. Kukkurainen ${ }^{1}$, M. Kauppi ${ }^{2}$, Y. van Eijk-Hustings ${ }^{3} .{ }^{1}$ Faculty of Business and Hospitality Management, Lahti University of Applied Sciences Ltd; ${ }^{2}$ Rheumatology Unit, Päijät-Häme Cetral Hospital, Lahti, Finland; ${ }^{3}$ Department of PatientandCare/ Clinical epidemiology and medical technology assessment (KEMTA), Maastricht UMC, Maastricht, Netherlands

Background: The dissemination of the EULAR-RN in the management of CIA have been completed in Europe and in the USA. ${ }^{2}$ The treatment is supposed to be carried out based on shared decision making (SDM). ${ }^{3}$ Lay versions of the recommendations and input from the patient organisations are essential in the integration of the recommendations and SDM ${ }^{4}$

Objectives: The aims of this study were to assess agreement with and application of, and identify barriers against implementing the EULAR-RN in the management of CIA iand to assess differences between individual Nordic countries.

Methods: A web-based survey was distributed using snowball sampling. Levels of agreement and application were assessed using a $0-10$ rating scale $(0=$ none, $10=$ full agreement/application). Reasons for disagreement with and barriers against applying each recommendation were sought. Differences between groups were assessed using the Kruskal-Wallis Test.

Results: A total of 318 patients from Finland participated in the survey. Their mean age was 52.1 years (SD 15.6). $47 \%$ had completed secondary education, $25 \%$ only primary and one third tertiary education. The mean duration of the disease was 17.7 years (SD 13.0), with a diagnosis of RA (63.5\%), AS or PsA $(29.8 \%, 6.7 \%$ respectively) and treated in general $(45 \%)$, university $(32 \%)$ or other hospitals. The median level of agreement was high, ranging from 8 to 10 in Finland 